\title{
Aulacid wasps (Hymenoptera: Aulacidae) of New Guinea, with descriptions of five new species
}

\author{
JOHN T. JENNINGS \& ANDREW D. AUSTIN
}

Centre for Evolutionary Biology and Biodiversity, and School of Earth and Environmental Sciences, The University of Adelaide, SA 5005, Australia.

\begin{abstract}
The little known aulacid fauna of New Guinea comprises six geographically isolated, endemic species. Previously known from a single species, Aulacus pterostigmatus (Szépligeti), three new species of Aulacus are described: A. enarotadi, A. sedlaceki and A. wau. In addition, Pristaulacus is recorded from New Guinea for the first time with the descriptions of $P$. kiunga sp. nov. and P. laloki sp. nov. A key to the New Guinea species is provided.
\end{abstract}

Key words: Evanioidea, Aulacus, Pristaulacus, taxonomy, parasitic wasps

\section{Introduction}

Aulacidae is a family of parasitic wasps that are endoparasitoids of wood-boring wasps (Xiphydriidae) and beetles (Cerambycidae and Buprestidae) (e.g., Carlson 1979; Gauld \& Bolton 1988; Smith 2001; Jennings \& Austin 2004; Jennings \& Deans 2006). Although at various times the Aulacidae have been treated as either a subfamily or group of the Evaniidae s.l., most recent studies regard them as a distinct family and probably the sister group to the Gasteruptiidae (e.g., Mason 1993; Jennings \& Austin 2000; Smith 2001; Basibuyuk et al. 2002; Jennings et al. 2004a,b; Jennings \& Deans 2006)

As with other members of the Evanioidea, aulacids are characterised by the high dorsal articulation of the metasoma on the propodeum, but these wasps are readily distinguished from the other families by the presence of fore wing vein $2 \mathrm{~m}$-cu (Gauld \& Bolton 1988), fore wing cross-vein 3r-m (Konishi 1990), and the presence of a metapostnotum (Jennings et al. 2004a,b,c). The Aulacidae currently comprises 189 valid species, including 65 species of Aulacus Jurine, 122 species of Pristaulacus Kieffer and two species of Panaulix Benoit (see Smith 2001; Jennings 2001; Jennings et al. 2004a,b,c; Turrisi 2004; Smith 2005a,b; Deans et al. 2006). Both Aulacus and Pristaulacus are 